\title{
Workshop menghindari plagiasi dengan teknik parafrase pada penulisan karya ilmiah mahasiswa tingkat akhir 2021
}

\author{
Marisa Fran Lina ${ }^{1 *}$, Lilik Supriyono ${ }^{2}$ \\ ${ }^{1}$ IAIN Salatiga \\ ${ }^{2}$ SMP N 2 Susukan \\ *Korespondensi (e-mail: marisafl@iainsalatiga.ac.id)
}

Received: 11-October-21; Revised: 15- October-21; Accepted: 8-November-21

\begin{abstract}
Scientific paper often becomes the toughest obstacle faced by students. This community service article was written based on a workshop with the same theme which aims to avoid plagiarism on writing scientific papers for final-year students in Salatiga with paraphrasing techniques. The workshop was held online via Zoom application and joined by 20 eightsemester students in Salatiga 2021 who had difficulties in writing their final assignments. The activities were: material presentation on paraphrasing techniques, question and answer session, paraphrasing techniques practice directly from scientific text sources according to the student's scientific field, and direct feedback/evaluation to students. At the end of the activity, the presenters as well as the authors distributed a link to check students' understanding questionnaires about paraphrasing techniques in general. From these activities, it can be concluded that the paraphrasing technique is very important for students and is needed to reduce the percentage of plagiarism check results. In addition, from the results of the questionnaire, overall, all participants understood and could practice well the paraphrase technique material from the Workshop.
\end{abstract}

Keywords: Avoid Plagiarism, Final-year students, Paraphrasing Technique

\begin{abstract}
Abstrak
Karya ilmiah sering sekali menjadikan kendala terberat yang dialami mahasiswa. Artikel Pengabdian ini ditulis berdasarkan Workshop dengan tema sama yang bertujuan untuk menghindari plagiasi dalam penulisan karya ilmiah mahasiswa semester akhir di Salatiga dengan teknik parafrase. Dalam Workshop tersebut diselenggarakan secara online melalui aplikasi Zoom dan diikuti oleh 20 mahasiswa semester 8 yang mengalami kesulitan di dalam penulisan tugas akhir. Adapun kegiatannya: melakukan pemaparan materi tentang teknik paraphrase, tanya jawab, mempraktikkan teknik tersebut secara langsung dari sumber teks ilmiah sesuai dengan bidang keilmuan mahasiswa, dan pemberian feedback/evaluasi langsung kepada mahasiswa. Di akhir kegiatan, pemateri sekaligus penulis menyebarkan link yang di dalamnya terdapat kuesioner pemahaman mahasiswa seputar teknik parafrase secara umum. Dari kegiatan tersebut dapat disimpulkan bahwa teknik parafrase sangat penting bagi mahasiswa dan sangat dibutuhkan untuk mengurangi prosentase hasil cek plagiasi. Selain itu dari hasil kuisioner, secara keseluruhan dari semua peserta memahami dan bisa mempraktekkan dengan baik materi teknik paraphrase dari Workshop tersebut.
\end{abstract}

Kata kunci: Mahasiswa Semester Akhir, Menghindari plagiasi, Teknik paraphrase

How to cite: Marisa Fran Lina, \& Lilik Supriyono. (2021). Workshop menghindari plagiasi dengan teknik parafrase pada penulisan karya ilmiah mahasiswa tingkat akhir 2021. Penamas: Journal of Community Service, 1(2), 66-76. https://doi.org/10.53088/penamas.v1i2.182 


\section{Pendahuluan}

Kompetensi penting yang harus dikuasai mahasiswa dalam mengembangkan dan menunjang ilmunya adalah skill berbahasa. Dalam berbahasa terdapat empat aspek yang harus dikuasai antara lain: mendengarkan, membaca, berbicara, dan menulis (Bintari, Sudiana, \& Putrayasa, 2014). Dari empat aspek berbahasa tersebut, aspek menulis merupakan aspek yang membutuhkan keterampilan khusus dan harus senantiasa dikembangkan mengikuti perkembangan zaman agar bisa menjadi sebuah karya ilmiah karena aspek menulis bukan aspek teoritis (Ningsih, 2020). Menulis dapat diartikan sebagai kegiatan yang sifatnya kompleks dengan mengintegrasikan berbagai kemampuan di dalamnya, misal visual-motor dengan kemampuan konseptual dan sangat dipengaruhi dengan kemampuan kognitif (Jamaris, 2014). Perkembangan menulis bisa terlihat dengan adanya latihan terus menerus, agar menjadikan tulisan yang runtut, padu dan berisi (Nurgiyantoro, 2014). Dengan demikian kegiatan menulis merupakan unsur yang sangat penting sebagai wujud dari aspek mendengarkan dan membaca berbagai sumber literasi sehingga bisa menghasilkan sebuah tulisan yang ilmiah yang di dalamnya membutuhkan latihan.

Aspek menulis agar dapat menghasilkan tulisan yang ilmiah bisa dikembangkan dengan menggunakan teknik parafrase. Parafrase itu sendiri merupakan kemampuan untuk mengungkapkan kembali suatu gagasan orang lain dengan bahasanya sendiri akan tetapi tidak menghilangkan maknanya (Aminuddin, 2010). Dengan begitu tujuan memparafrase adalah untuk menyederhanakan kalimat pengarang agar lebih mudah dipahami.

Adapun beberapa penelitian yang berhubungan dengan teknik parafrase adalah sebagai berikut: Penerapan Teknik Parafrase Diary Tingkatkan Keterampilan Menulis Geguritan pada Peserta Didik SMK , Meningkatkan Kemampuan Guru Bahasa Inggris Menulis Karya IImiah dengan Pelatihan Parafrase dan Mengutip untuk Menghindari Tindak Plagiasi (Wulandari et al. 2020), Peningkatan Kemampuan Menyimak melalui Metode Parafrase pada Mahasiswa Semester I Program Studi Pendidikan Bahasa dan Sastra Indonesia Institut Pendidikan Tapanuli Selatan (Harahap 2019), Pembelajaran Menulis Teks Cerpen melalui Teknik Parafrase Lagu Populer di Sekolah Menengah Atas (Waningyun, Suwandi, \& Setyawan 2018), Penerapan Strategi Parafrase Terarah untuk Meningkatkan Kemampuan Menulis Karangan Singkat Siswa Kelas IV SD Negeri 014 Silikuan Hulu Kecamatan Ukui (Sitorus 2016), dan Analisis Penggunaan likae atau Parafrase dalam Percakapan Bahasa Jepang (Romando 2017).

Dari hasil workshop dengan mahasiswa tingkat akhir di Salatiga dalam penulisan karya ilmiah dengan teknik parafrase diperoleh data bahwa mayoritas mahasiswa sudah mengetahui teknik parafrase, namun masih kesulitan untuk mensintesis dari kalimat penulis agar menjadi sebuah tulisan dengan gaya bahasanya sendiri tanpa menghilangkan makna dari penulis. Hal ini membuktikan jika dalam menulis membutuhkan kemampuan kognitif dan literasi yang banyak serta latihan terus menerus. 
Dari hal tersebut, peneliti yang juga menjadi pembimbing skripsi mahasiswa dan tutor Academic Writing Course di Lembaga Bahasa di IAIN Salatiga mencoba mengadakan pelatihan parafrase kepada para mahasiswa tersebut agar lebih bisa mempraktekkan teknik parafrase guna mengurangi tingginya prosentase cek plagiasi dalam menulis ilmiah. Begitu pentingnya teknik ini, sehingga dengan mengajarkannya kepada para mahasiswa diharapkan dapat membantu mereka mempraktekkan sendiri dalam menulis karya ilmiah yang lebih kredibel.

Berdasarkan analisa di atas, maka dapat ditarik rumusan masalahnya yaitu bagaimana menggunakan teknik parafrase untuk menghindari plagiasi pada penulisan karya ilmiah mahasiswa tingkat akhir di Salatiga. Adapun tujuan utama dari program pengabdian yaitu: (1) memberikan pengetahuan terhadap mahasiswa tingkat akhir di Salatiga tentang teknik parafrase; (2) memberikan kegiatan pelatihan teknik parafrase untuk menghindari plagiasi; (3) mahasiswa dapat menulis karya ilmiah dengan menggunakan teknik parafrase.

Dengan adanya kegiatan pengabdian pada masyarakat ini, hasilnya akan memberikan kontribusi terhadap dunia akademis di tingkat perguruan tinggi. Adapun hal tersebut dapat diperinci sebagai berikut:

1. Para mahasiswa mendapatkan pendalaman materi tentang teknik parafrase sehingga dapat meningkatkan kemampuan menulis karya ilmiah

2. Meningkatkan kualitas karya ilmiah mahasiswa di lingkungan perguruan tinggi

3. Mendukung keberhasilan program rendah tingkat plagiasi pada level fakultas

\section{Metode Pengabdian}

Pengabdian ini menggunakan metode kualitatif dengan peneliti terjun secara langsung ke lapangan agar hasilnya benar-benar akurat. Adapun tujuan dari pengabdian ini yaitu memberikan Workshop tentang cara menghindari plagiasi dengan menggunakan teknik parafrase pada penulisan karya ilmiah mahasiswa mahasiswa semester akhir di Salatiga 2021

\section{Sasaran yang dituju}

Adapun sasaran yang dituju dalam pengabdian ini yaitu 20 mahasiswa semester akhir di Salatiga 2021 yang belum menyelesaikan tugas akhir perkuliahan. Kegiatan pengabdian ini disosialisasikan melalui media sosial sehingga para mahasiswa tersebut mendaftar melalui narahubung yang tercantum pada flyer kegiatan. Workshop ini dilakukan melalui Zoom yang telah disebarluaskan linknya ke 20 mahasiswa melalui WhatsApp.

\section{Tahap persiapan}

Adapun pelaksanaan workshop dilakukan pada:

Hari dan tanggal : Selasa, 31 Agustus 2021

Waktu :09.45-12.00

Link Zoom

https://zoom.us/j/4162652783?pwd=TmFSZnRPOVZIR1BJY1N1czRHYkJNQT09 
Tema

Peserta

Materi

Bahan materi

\section{: PELATIHAN PARAFRASE}

: Mahasiswa tingkat akhir di Salatiga 2021

: 5 Teknik parafrase dan 3 latihan yang sudah disiapkan dalam bentuk PowerPoint (PPT)

\section{Tahap pelaksanaan}

: Materi tentang teknik parafrase dan latihan tentang penerapannya

Untuk tahap pelaksanaannya semua peserta masuk melalui link zoom berikut: https://zoom.us/j/4162652783?pwd=TmFSZnRPOVZIR1BJY1N1czRHYkJNQT09 sebagai sarana pertemuan secara tatap muka online. Menyiapkan laptop atau HP beserta jaringannya, PowerPoint sebagai materi, buku, dan bolpoin. Adapun susunan acaranya: Pembukaan, sambutan panitia, dan meeting sesuai materi dilanjutkan pelatihan parafrase serta evaluasi dari hasil memparafrase.

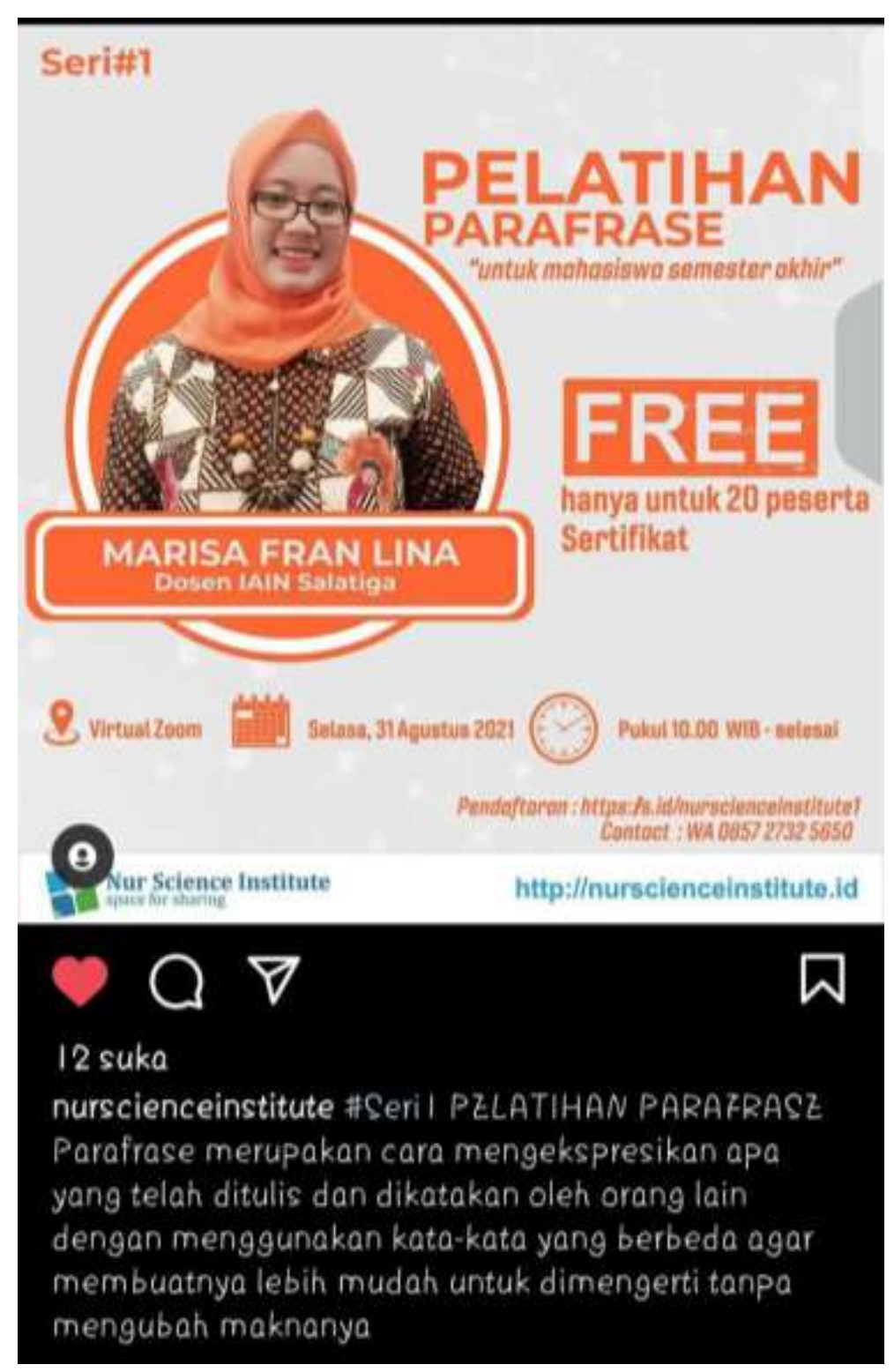

Gambar 1. Flyer Kegiatan Workshop Menghindari Plagiasi dengan

Teknik Parafrase pada Penulisan Karya IImiah di Instagram 
Tabel 1 Pelaksanaan Workshop Menghindari Plagiasi dengan Teknik Parafrase pada Penulisan Karya IImiah

\begin{tabular}{cl|}
\hline No & Kegiatan \\
\hline 1 & Pembukaan, Pengenalan moderator, Pengenalan Pemateri \\
2 & Pemaparan Pemateri \\
3 & Latihan, Feedback dan Tanya Jawab \\
4 & Pengisian Form tentang Pemahaman Teknik Parafrase \\
5 & Penutup dan Absensi \\
\hline
\end{tabular}

\section{Evaluasi Kegiatan}

Kegiatan ini dilakukan dengan cara memberikan pelatihan teknik parafrase disertai dengan contoh dan kemudian langsung memberikan latihan beserta feedback untuk mengetahui sejauh mana pengetahuan dan hasil pemahaman dari penyampaian workshop dalam pengabdian ini dengan kuesioner.

\section{Hasil Pengabdian}

\section{Sambutan}

Marisa Fran Lina, M.Pd., selaku penulis pertama dan pemberi materi pada kelas pengabdian ini menyambut para peserta Zoom Meeting serta memberikan penjelasan tentang pentingnya workshop untuk menghindari plagiasi dengan teknik parafrase dalam penulisan karya ilmiah. Disamping itu beliau memberikan ucapan terimakasih atas partisipasi aktif mahasiswa tingkat akhir di Salatiga 2021, dan berharap antusiasme dari para peserta akan terus berlanjut pada kegiatan workshop serupa ke depannya.

\section{Selayang Pandang dan Pengantar Materi}

Overview dan penyampaian materi diberikan oleh Marisa Fran Lina, M.Pd.. Dimulai dari sekilas latar belakang pentingnya workshop teknik menulis parafrase untuk menghindari plagiasi dalam karya ilmiah. Tren cek plagiasi pada karya ilmiah memang mulai ramai diperbincangkan di dunia akademik terutama di ranah perguruan tinggi. Dalam lingkungan perguruan tinggi pada fakultas peserta workshop ini menghendaki tingkat plagiasi hanya ditoleransi sebanyak maksimal $30 \%$. Tentu. hal ini dianggap berat oleh para mahasiswa yang hidup di era serba digital ini.

Berdasarkan hal tersebut di atas, akhirnya menjadi tonggak bagi penulis sekaligus pemateri untuk mengadakan workshop ini. Banyak mahasiswa yang mengeluhkan bagaimana cara melakukan teknik parafrase yang benar ketika mereka melakukan pengutipan pada karya ilmiah. Hal ini tentunya tidak lain adalah untuk mengurangi tingginya presentasi hasil cek plagiasi dan agar lebih menghasilkan karya ilmiah yang lebih berkualitas.

Parafrase sendiri merupakan teknik yang digunakan untuk penulis karya ilmiah menulis kembali gagasan penulis lain dengan kalimatnya sesuai perspektifnya sendiri dan disajikan berbeda namun tidak mengubah makna dari penulis aslinya. Adapun teknik parafrase yang dipakai pada workshop kali ini adalah sebagai berikut: 


\section{Teknik \\ Parafrase}

1. Merubah dari klausa ke frase (atau sebaliknya)

2. Merubah dari katimat langsung menjadi kalimat tidak langsung (atau sebaliknya)

3. Merubah dari katimat aktif menjadi katimat pasif (atau sebaliknya)

4. Merubah sinonim

5. Merubah bentuk kata

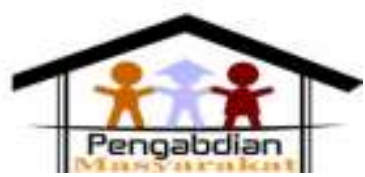

Gambar 2. Temuan yang Dijadikan Materi Utama Workshop Menghindari Plagiasi dengan Teknik Parafrase pada Penulisan Karya IImiah

Selanjutnya, dari hasil tersebut di atas menjadi bahan utama pada workshop teknik parafrase ini. Kelima teknik tersebut kemudian dikembangkan dan coba diaplikasikan dalam memparafrasakan teks-teks ilmiah yang sering mahasiswa temui ketika menulis karya ilmiah. Adapun cara pengaplikasian teknik parafrase akan dijabarkan pada poin selanjutnya.

\section{Praktik Teknik Parafrase}

Pada tahapan ini pemateri memaparkan materi yang sudah disiapkan sebelumnya dengan PowerPoint (PPt). PPt tersebut berisi tentang sekilas pengertian parafrasa, teknik melakukan parafrase disertai dengan contohnya, pendalaman materi, dan prinsip-prinsip penting dalam teknik parafrase,

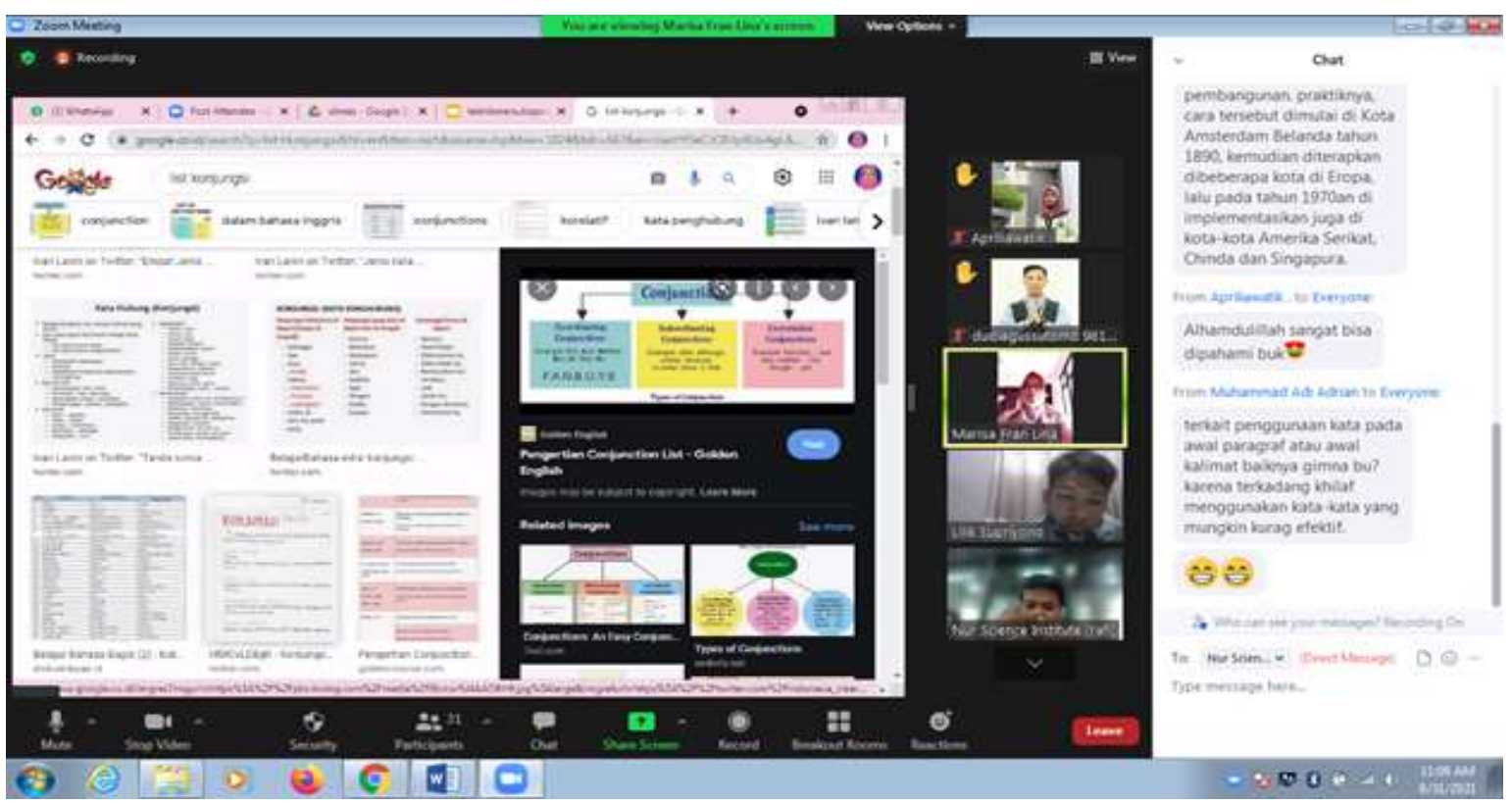

Gambar 3. Pemateri menjelaskan macam-macam konjungsi untuk memperkaya kosakata dalam parafrase 
Sesudah materi menjelaskan tentang kelima teknik parafrase tadi dan memberikan contoh-contoh mudah dalam penggunaannya pada beberapa kalimat sederhana, beliau meminta peserta workshop untuk berdiskusi mengenai materi tersebut dan mempersilahkan jika ada pertanyaan seputar parafrase. Setelah sesi tanya jawab usai, dilanjut pembahasan sebuah teks ilmiah dan bagaimana cara parafrasenya. Baru setelah itu, pemateri memberi kesempatan peserta melakukan parafrase pada teks ilmiah yang disediakan sesuai dengan bidang mereka yaitu ekonomi. Salah satu peserta perform dan menampilkan hasil pekerjaan parafrasenya, lalu pemateri mereview dan memberikan feedback.

Tabel 2. Tahapan Kegiatan pada Workshop Teknik Parafrase

\begin{tabular}{lll}
\hline \multicolumn{1}{c}{ Kegiatan } & \multicolumn{1}{c}{ Langkah-langkah } & \multicolumn{1}{c}{ Metode } \\
\hline $\begin{array}{l}\text { Orientasi Pemahaman } \\
\text { mahasiswa tentang teknik } \\
\text { parafrase }\end{array}$ & $\begin{array}{l}\text { Memberikan materi-materi } \\
\text { tentang sekilas teknik } \\
\text { parafrase beserta } \\
\text { contohnya }\end{array}$ & $\begin{array}{l}\text { ceramah partisipatoris } \\
\text { apersepsi pembelajaran } \\
\text { brainstorming }\end{array}$ \\
Implementasi & $\begin{array}{l}\text { Memberikan latihan } \\
\text { penggunaan teknik } \\
\text { parafrase kepada }\end{array}$ & problem solving \\
& $\begin{array}{l}\text { mahasiswa } \\
\text { Memberikan evaluasi atau } \\
\text { feedback dari hasil latihan } \\
\text { kuis-kuis }\end{array}$ & pengawasan \\
penengah pro-kontra \\
individual konseling \\
Refleksi & Mritik dan saran serta & Apresiasi \\
& motivasi & \\
\hline
\end{tabular}

Dalam workshop ini mahasiswa sangat bersemangat mengikuti acara demi acara. Mahasiswa juga mengerjakan latihan yang diberikan pemateri secara langsung. Keaktifan mereka terlihat dari room chat yang penuh dengan pertanyaan dan feedback dari hasil penjelasan pemateri.
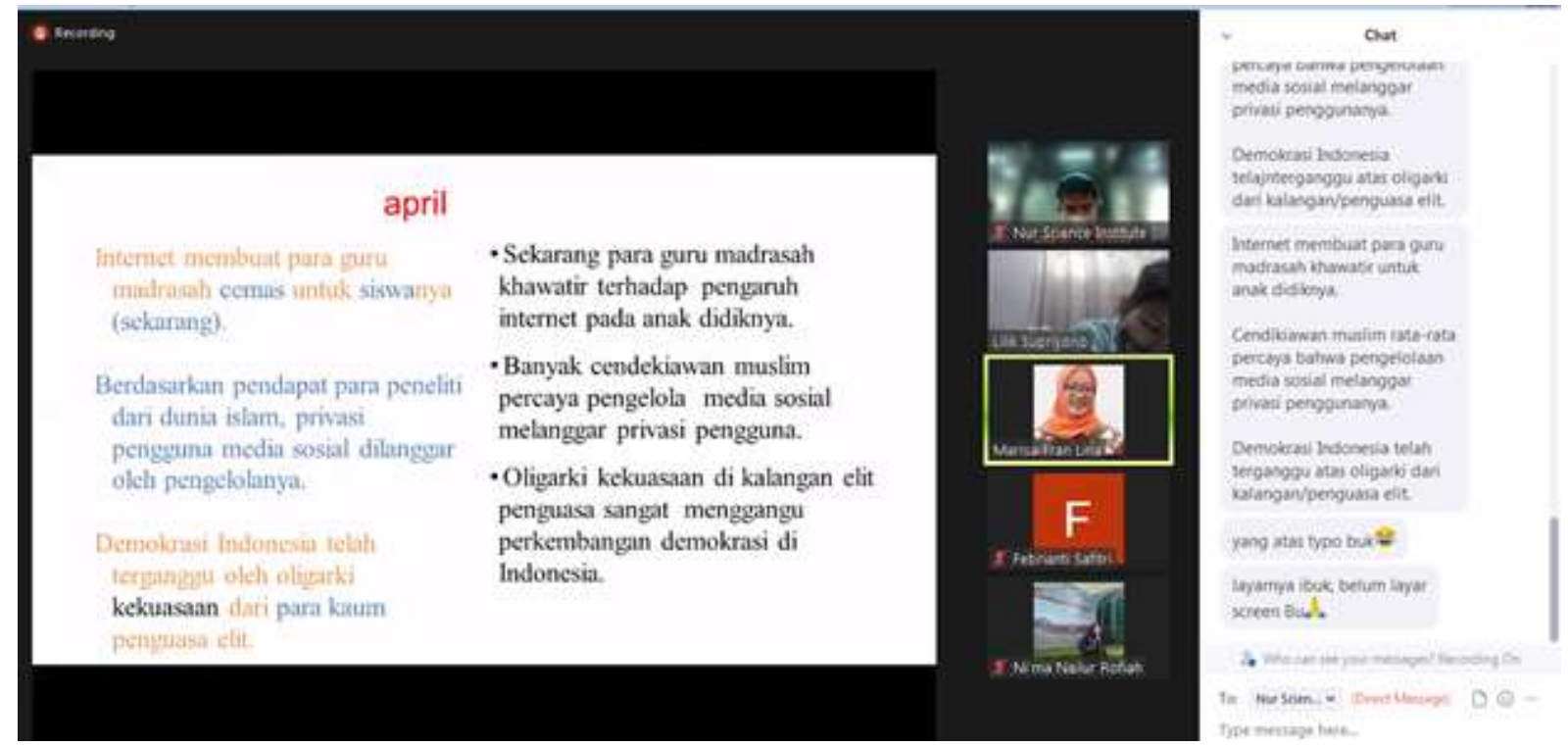

Gambar 3. Salah satu peserta mengerjakan latihan teknik parafrase dan pemateri memberikan feedback 


\section{Kesimpulan}

Dari hasil workshop ini dapat diambil kesimpulan bahwa dalam pelaksanaannya, sebagian besar peserta mampu memahami materi tentang teknik parafrase terlihat dari hasil kuesioner melalui Google Form pasca kegiatan berlangsung. Beberapa peserta juga terlibat aktif dalam sesi tanya jawab terkait teknik parafrase. Peserta yang mempraktekan teknik parafrase pada sesi latihan, dinilai cukup berhasil menggunakan teknik yang telah diajarkan. Peserta mengakui bahwa teknik ini sangat penting bagi mahasiswa dan sangat dibutuhkan untuk mengurangi prosentase hasil cek plagiasi. Diharapkan follow up dari kegiatan ini akan ada kegiatan-kegiatan lanjutan yang serupa guna meningkatkan kualitas karya ilmiah mahasiswa

\section{Ucapan Terimakasih}

Kami selaku penulis mengucapkan terima kasih kepada Nur Science Institute yang telah mendukung pelaksanaan kegiatan pengabdian ini dari segi persiapan kegiatan, penyedia platform workshop dan ketersediaan subjek penelitian.

\section{Referensi}

Aminuddin. 2010. Pengantar Apresiasi Karya Sastra. Bandung: Sinar Baru Algensindo.

Bintari, N. L. G. R. P., Sudiana, I. N., \& Putrayasa, I. B. (2014). Pembelajaran Bahasa Indonesia Berdasarkan Pendekatan Saintifik (Problem Based Learning) Sesuai Kurikulum 2013 di Kelas VII SMP Negeri 2 Amlapura. Jurnal Pendidikan dan Pembelajaran Bahasa Indonesia, 3(1).

Harahap, S. M. (2019). Peningkatan Kemampuan Menyimak Melalui Metode Parafrase Pada Mahasiswa Semester I Program Studi Pendidikan Bahasa Dan Sastra Indonesia Institut Pendidikan Tapanuli Selatan. Jurnal Education And Development, 7(1), 32-32. doi: 10.37081/ed.v7i1.766

Jamaris, M. (2014). Formal multiple intelligences assessment instruments for 4-6 years old children. American Journal of Educational Research, 2(12), 1164-1174.

Ningsih, K. D. (2020). Peningkatkan Keterampilan Menulis Teks Eksplanasimenggunakan Media Pembelajaran Gambar Fenomena Alam Pada Kelas VIII B Mts Negeri I Purworejo Semester 1 Tahun Pelajaran 2018/2019. DWIJALOKA Jurnal Pendidikan Dasar dan Menengah, 1(1).

Nurgiyantoro, B. (2014). Penggunaan Ungkapan Jawa dalam Kumpulan Puisi Tirta Kamandanu Karya Linus Suryadi (Pendekatan Stilistika Kultural). Litera, 13(2).

Romando, R. R. (2017). Analisis Penggunaan likae atau Parafrase dalam Percakapan Bahasa Jepang. Chi'e: Journal of Japanese Learning and Teaching, 5(1), 19-25. doi: 10.15294/chie.v5i1.10473

Sitorus, K. (2018). Penerapan Strategi Parafrase Terarahuntuk Meningkatkan Kemampuan Menulis Karangan Singkat Siswa Kelas IV SD Negeri 014 Silikuan Hulukecamatan Ukui. Primary: Jurnal Pendidikan Guru Sekolah Dasar, 5(2), 294303. doi: 10.33578/jpfkip.v5i2.3717.

Waningyun, P. P., Suwandi, S., \& Setyawan, B. (2018). Pembelajaran Menulis Teks Cerpen Melalui Teknik Parafrase Lagu Populer di Sekolah Menengah 
Atas. Scholaria: Jurnal Pendidikan Dan Kebudayaan, 8(2), 180-188. doi: 10.24246/j.js.2018.v8.i2.p180-188.

Wantoro, A. W. (2021). Penerapan Teknik Parafrase Diary Tingkatkan Keterampilan Menulis Geguritan Pada Peserta Didik SMK. Kawruh: Journal of Language Education, Literature and Local Culture, 3(1), 1-11. doi: 10.32585/kawruh.v3i1.1426.

Wulandari, B. A., Adrefiza, A., Norawati, R., \& Fortunasari, F. (2020). Meningkatkan Kemampuan Guru Bahasa Inggris Menulis Karya Ilmiah Dengan Pelatihan Parafrase Dan Mengutip Untuk Menghindari Tindak Plagiasi. Jurnal Karya Abdi Masyarakat, 4(1), 173-176. doi: 10.22437/jkam.v4i1.9849. 